University of Wollongong

Research Online

Faculty of Informatics - Papers (Archive)

Faculty of Engineering and Information

Sciences

2010

\title{
What's your contribution? An online system for assessing each member's participation in team based projects
}

\author{
Peter James Vial \\ University of Wollongong, peterv@uow.edu.au \\ Zhihao Zhang \\ University of Wollongong \\ Montserrat Ros \\ University of Wollongong, montse@uow.edu.au \\ Christian Ritz \\ University of Wollongong, critz@uow.edu.au \\ Geoffrey W. Trott \\ University of Wollongong, gwt@uow.edu.au
}

Follow this and additional works at: https://ro.uow.edu.au/infopapers

Part of the Physical Sciences and Mathematics Commons

\section{Recommended Citation}

Vial, Peter James; Zhang, Zhihao; Ros, Montserrat; Ritz, Christian; and Trott, Geoffrey W.: What's your contribution? An online system for assessing each member's participation in team based projects 2010. https://ro.uow.edu.au/infopapers/3530 


\title{
What's your contribution? An online system for assessing each member's participation in team based projects
}

\author{
Abstract \\ Team based subjects in Engineering occur within the School of Electrical, Computer and \\ Telecommunications Engineering in second and third year undergraduate degrees. In such subjects, \\ students work in teams of between five and ten students to propose and develop engineered products for \\ a target market place (chosen from different themes) with a small budget allocated for purchasing \\ materials and devices. In practice, all students cannot make exactly the same contribution as each other, \\ so a system to allocate marks for individual's contribution has been previously developed and employed \\ within the school. This system is called the Fair Contribution Sheet (FCS) and a paper-based form has \\ been developed and deployed within these subjects for many years. This paper outlines the FCS system \\ and describes the development of an electronic form based equivalent, which was first deployed in 2010. \\ The deployed system was developed using Java and Java Server pages (JSP). A survey of students, who \\ used this software, was conducted. Some of these students had previously used the paper-based FCS \\ and their perception of the differences between the electronic and paper based versions, along with other \\ results, are presented in this paper. The paper also compares the use of the paper and electronic versions \\ from the viewpoint of the subject coordinator.

\section{Disciplines} \\ Physical Sciences and Mathematics

\section{Publication Details} \\ P. J. Vial, Z. Zhang, M. Ros, C. H. Ritz \& G. W. Trott, "What's your contribution? An online system for \\ assessing each member's participation in team based projects," in The 4th International Conference on \\ Signal Processing and Communication Systems, 2010, pp. 1-8.
}




\title{
What's your Contribution? An online system for assessing each member's participation in team based projects
}

\author{
Peter James Vial, Zhihao Zhang, Montse Ros, Christian Ritz, Geoff Trott \\ University of Wollongong
}

\begin{abstract}
Team based subjects in Engineering occur within the School of Electrical, Computer and Telecommunications Engineering in second and third year undergraduate degrees. In such subjects, students work in teams of between five and ten students to propose and develop engineered products for a target market place (chosen from different themes) with a small budget allocated for purchasing materials and devices. In practice, all students cannot make exactly the same contribution as each other, so a system to allocate marks for individual's contribution has been previously developed and employed within the school. This system is called the Fair Contribution Sheet (FCS) and a paper-based form has been developed and deployed within these subjects for many years. This paper outlines the FCS system and describes the development of an electronic form based equivalent, which was first deployed in 2010. The deployed system was developed using Java and Java Server pages (JSP). A survey of students, who used this software, was conducted. Some of these students had previously used the paper-based FCS and their perception of the differences between the electronic and paper based versions, along with other results, are presented in this paper. The paper also compares the use of the paper and electronic versions from the viewpoint of the subject coordinator.
\end{abstract}

Keywords: Java, JSP, Team or Group Work assessment, Fair Contribution Sheet

\subsection{INTRODUCTION}

Professional engineers from different engineering disciplines generally work in teams on large projects. To develop or build a system, individual tasks and stages (or phases) are identified and illustrated using a Gantt Chart or Pert Diagram. The engineers then work together on planning, developing, constructing and testing the system designed for a particular purpose or function. Typically the time and effort spent on these projects is billed via time sheets, which are then charged to the project's budget.

When educating undergraduate engineers within the School of Electrical, Computer and Telecommunications Engineering (SECTE) at the University of Wollongong (UOW) there are no time sheets. Instead, use is made of assessment tasks (also called deliverables) and associated assessment marks. The basic underlying factor here is that a project undertaken at the University must, by its very nature, be a team or group work project. The currency used (instead of real money) is the assessment allocated to individual students within a team or group.
The methodology used to do this at UOW, is via a peer assessment mechanism called the Fair Contribution Sheet (FCS). This FCS is based on the idea that all the students in the team should agree on the relative contributions of each member of the team to a particular phase or stage of a project's development. Teams should engage in an open and frank discussion of each individual's contribution to the project since the last FCS sheet was submitted. This discussion must take place because of the rule that only one student can have a median score (of 20). Then the team fills in a form, with signatures, indicating each individual's agreed contribution to the overall team's performance. It is the combined series of FCS scores that is then used to determine the individual's final assessment mark for the project. These scores are checked for signatures and recorded by the coordinator for each student every time a FCS is submitted.

The process appears to lend itself to computer automation. Instead of all students meeting in a physical location, the same interaction could occur over the Internet. In fact, a Java based program using Java Server Pages (JSP) and a tomcat server was 
developed in 2009 and implemented in early 2010 within the third year management and design project within SECTE at UOW.

This paper outlines the development and implementation of the Electronic FCS in Java, JSP and using a tomcat server (from the APACHE free software foundation). The paper is structured as follows. Section 2 introduces various approaches in the literature to assessing engineering project work in a University context and where Internet based assessment techniques have been deployed. Section 3 introduces the reasons for the FCS, and how it satisfies various quality attributes of the University of Wollongong and of Engineering accreditation bodies (in Australia this is Engineers Australia) for peer assessment as well as the known shortcomings of the paper based FCS. Section 4 describes the development in Java of the electronic FCS and the features implemented using the available Java packages. Section 5 presents results of a survey conducted in the final weeks of the system's first deployment amongst third year students. Section 6 is the conclusion and future work.

\subsection{TEAM BASED ASSESSMENT PRACTICES}

In [1] a software team assessment program is introduced for multidisciplinary (four different engineering majors from electrical and mechanical engineering) in large groups (6-10 students). This software allows team members and instructors to assess the individual performance in a major design project. It is not performed in a face to face manner (involving negotiation) and the formula used to provide peer and instructor assessment is quite complex. In [1], they indicate that they work on one of three major subsystems which comprise a major design project. Three to four teams (termed a division) are then grouped together to work on an overall project. This contrasts to the system used at UOW where a set of themes are provided and Teams put forward proposals which are accepted or rejected by a selected group of academic staff. These projects are then pursued by the team in direct competition with other teams with a major trade fair at the end of the second semester. This difference in approach makes comparison difficult, however it is interesting to note that in [1] they indicate, in their conclusion, that the online system provides more data than their previous paper based system did with a corresponding increase in other problems which the paper based system had masked. Another difference to UOW's approach is students can rate each other as having contributed equally to the project. The authors in [1] openly admit that peer pressure can unfairly bias the peer assessment as well as factors such as collusion (assessment based on formed friendships or agreements regardless of actual performance), personality conflicts (which need to be dealt with by an instructor), or simply students not being aware of each others contributions (because they never meet with other team members to discuss it and become involved in direct marks negotiation). While the formula provided is interesting, it is rather too complex. Also, UOWs' approach maintains that the best judges of individual performance within the team must be those who actually contribute to the team's overall performance (where the team's overall performance can be judged on academic and subjective basis by academic staff).

In [2] a software program called SPARK ${ }^{\text {PLUS }}$ is presented which allows for peer related assessment of group projects. This has been developed at the University of Technology, Sydney (UTS), Australia with collaboration from the University of Sydney, Australia, by Mark Freeman, Darrall Thompson, Keith Willey, Mike Howard and Anne Gardner. Research papers have been published using various versions of this software in [3-5]. They outline how their software is used in various project based learning subjects catering for the detection of so called 'free rider' students (who contribute very little to the overall team projects), to using these tools in face to face negotiation of student contributions and how this affects the overall achievement of team learning experiences (such as achieving collaboration within the team). These papers present the methodology and case studies of using this elaborate software package to allow for direct interaction and assessment by the team members who they correctly argue are best placed to assess individual contributions to the team project outcomes. In [3] they concentrated on the elimination of the free riders by a process which did not include any face to face processes (all the peer assessment was done anonymously using the SPARK software and formulas very similar to those presented in [1]). Later in [5] they used the software anonymously for the Requirement Specification but then had all students form back together to reflect on their evaluations and that of their fellow team members. This was done especially in relation to how they would do the task differently in light of their peer assessment. However, this did not actually involve direct negotiation of the teams assigned assessment marks as is the requirement using the UOW scheme of fair contribution sheets (paper based or electronic forms). 


\subsection{The FCS and Developed Student Attributes}

The UOW has outlined various graduate qualities which engineering students need to develop during completion of their various course work components. These qualities include attributes that are required by Engineers Australia who accredit the UOW Engineering degrees.

Two of the UOW graduate qualities mentioned in the project based design subjects are Team Member and Effective Communicators. From the Subject Outline for the third year Design and Management Graduate Qualities section the Team Member Graduate Quality is defined as the "Ability to function effectively as an individual in multi-disciplinary and multicultural teams with the capacity to be a leader or manager as well as an effective team member"[6]. In the same document, the Graduate Quality of Effective Communicators is defined as the "Ability to communicate effectively, not only with engineers but also with the community at large"[6]. These two Graduate qualities which have been chosen by the UOW within the engineering school with reference to those required for accreditation by Engineers Australia, imply that engineers must be able to communicate, not just with the general community who employ their services but with each other. They do this in a multi-disciplinary manner and in direct and frank discussion (either electronically or face to face). As students will one day become practicing engineers, they need to be given opportunities to develop these skills within the constructs and constraints of the University teaching and learning environment.

The UOW FCS provides an opportunity for engineering students to interact in teams and employ direct negotiation over their individual contribution to the team's overall result. These students, ideally, would behave by assertively demonstrating why they think they have contributed more, substantiated by their mandatory record keeping (using log books). After this negotiation, all team members are required to sign their acceptance of the peer assessed marks for the FCS. These marks are then used in the assessment process to distribute signed bonus marks to individual team members based on the overall team marks achieved for deliverables assessed by academic staff at UOW.

\subsection{Development of the Electronic FCS}

\subsection{The Basic rules of the FCS}

The previous paper based FCS used has written on it the calculation for the total FCS (the rule is the number of students in the team multiplied by 20), a box for the assigned score with students' name and students' signature, and details such as team name, team number and which numbered FCS it is (number 1 to 11). At the bottom of the sheet it outlines the rules. These state that only one student can get a 20, all scores must be integers, and the total must add up to $20 \mathrm{~N}$, where $\mathrm{N}$ is the number of team members.

\subsection{The paper based FCS}

The paper based system was prone to administrative problems. Firstly, every student needed to sign the sheet to indicate that they knew what mark the team had assigned. This was easily circumvented by students pre-signing multiple sheets and allowing smaller groups of students to assign the marks. This was strongly discouraged however it was impossible to ensure compliance, and it may be that many teams had used this technique without academic staff being aware of it. Secondly, some teams submitted sheets where more than one student had a score of 20 , requiring direct intervention by the academic staff administering the design subject. Thirdly, some students gave themselves fractions, when integers were only allowed, again requiring academic staff intervention. Fourthly, as the number of students increased more teams were required and extra administration was required in data entry of the FCS scores into a spreadsheet database. As a result of these factors it was decided in 2009 that an electronic FCS would be pursued for implementation in the third year engineering design and management subject during the first of two semesters (Autumn) during 2010 at UOW.

\subsection{The Electronic based FCS}

The programming language selected was Java. Java was chosen because it easily incorporates the client/server model required for an internet application and it was a language that engineering academic staff at UOW were familiar with. For the server tomcat[7;8] version 6 was selected as it was based on Java, had a built in Java Server Pages (JSP) compiler and is freeware[7;9]. JSP was used primarily because it can interface with built in objects with Java Servlets[10] within a session and it provides a simple interface for students and academic staff to use (though the system we implemented lacks any use of colour). The Netbeans 6.7 [11] Integrated Development Environment (IDE) was chosen to setup the project using Java Servlets[10] for different functions of the application, while Suns Java Development Kit (JDK) was used for Java 6 software development[12]. 
Figure 1 shows the basic functions of the electronic FCS. It includes a login script (using a JSP file), and a text file (using JSON Object text file constructs, which makes it easy to read for Java and for administrators of the software[13]) which contains individual entries of students user identification, tutor's (academic staff) user identification, associated passwords, which team the students are in and which team member is the assigned team leader for the FCS. The file is called user.txt, and is read when the first call is made to the internet application by any of the authenticated users of the system (most likely to be the academic staff member who administers the system). Upon this first call the database is initialized with all team members having FCS scores of zero assigned.

The team leader sees a different screen to other team members because only the team leader can input the individual scores for the team members. This should only be done after a team meeting has occurred to discuss and negotiate the individual scores. In the initial version, the team leader entered the scores without the need to state that such a meeting has occurred. Future versions (Spring 2010) will incorporate a toggle push button to indicate that the team leader affirms that such a discussion has occurred (see Section 6). When the team leader enters the scores, the electronic FCS checks that all the criteria for the FCS distribution have been satisfied (only one 20, all scores sum to correct value, no fractions) and only accepts the scores for voting if no errors are found. Figure 2 shows the team leaders screen shot for Team 1 after these scores have been entered.

The individual team members (including the team leader) must vote using their unique digital signatures (implemented using JSP and a Java Servlet called PostDigitalSignature dedicated to checking that the correct signature has been entered). Team members can vote 'yes' or 'no' for the indicated scores that have been entered by the team leader.

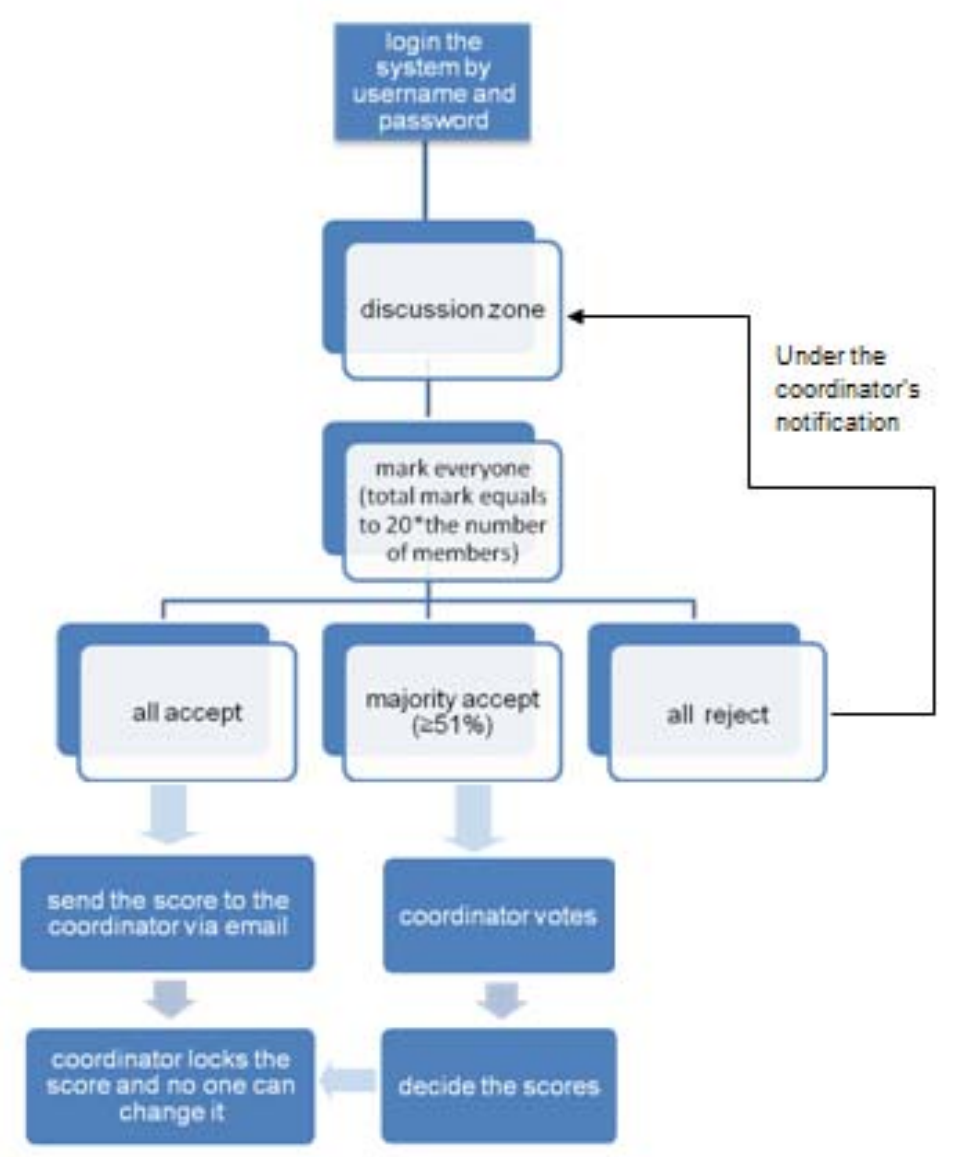

Figure 1: The basic functions of the electronic FCS 


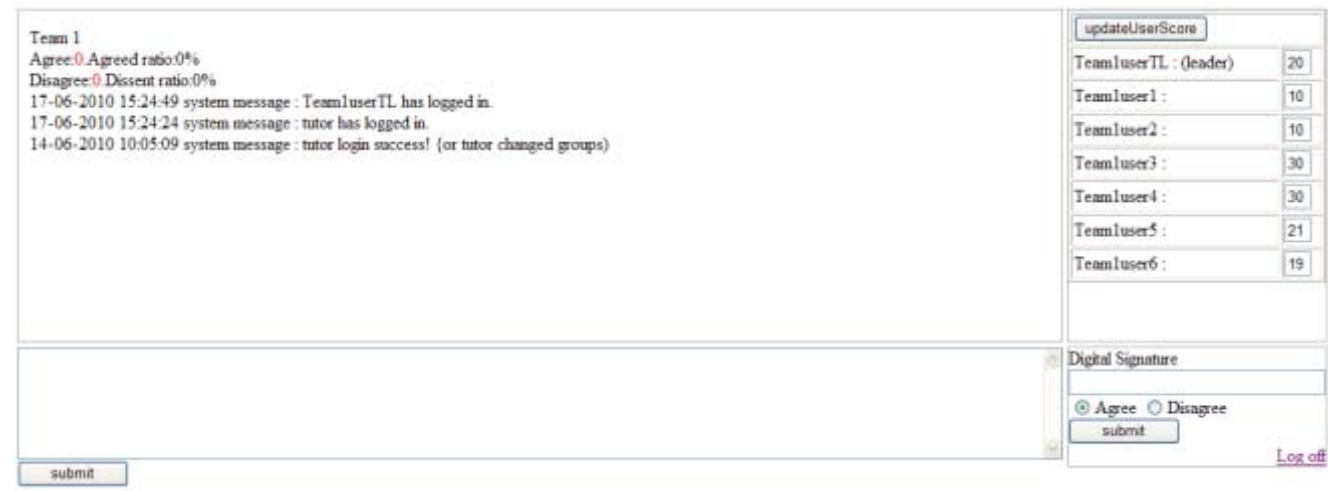

Figure 2: Team Leader after entering individual scores

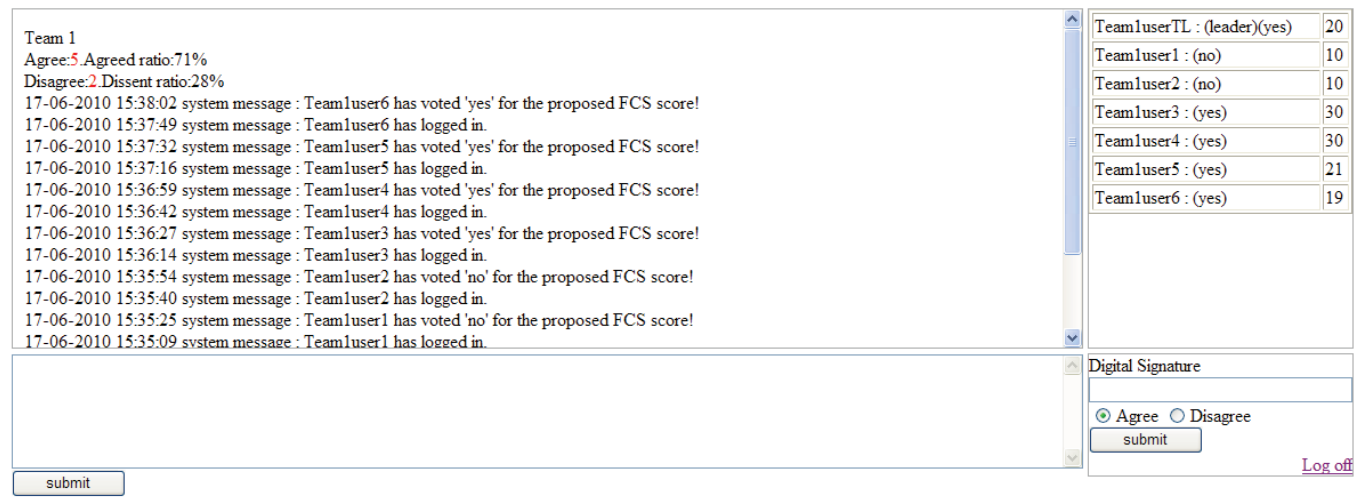

Figure 3: Team 1 User 1 screen shot after voting 'yes' and after all other team members have voted for the entered individual scores either 'yes' or 'no'

Figure 3 shows the state of voting after all team members have voted. Team1user1 and Team1user2 are the only team members to vote 'no', all the others have voted 'yes'. In most cases all team members vote 'yes'. If that occurs the vote is automatically saved and an email is sent to all team members and the academic staff member (called the tutor). The situation shown in Figure 3 will not result in an accepted FCS submission without direct intervention from the academic staff member/tutor. This will occur normally at the request of one of the team members though it could occur as a result of the coordinator reading the messages logged by the students during the process of voting. The academic staff member/tutor will need to access the FCS system and give permission for the team leader to accept a majority vote. The majority vote pushbutton is located in the right hand corner of the screen and a message is generated for all of Team 1 to read indicating that an intervention has occurred.

Once the academic staff member/tutor has enabled the majority vote the Team leader will see a screen where the team leader can now submit the final FCS scores for all Team 1 members using a submit pushbutton. This then results in the scores being saved and an email is sent to all team members and the academic staff member/tutor.

This process is repeated for all the teams registered in the electronic FCS. The academic staff member/tutor can determine which teams have submitted and which have not by looking at the FCS application web page showing a list of teams and the teams submission status. Those teams that have submitted will have the word 'submitted' next to them in brackets, allowing the academic staff member/tutor to give attention to those teams still involved in the FCS process. In addition the academic staff member/tutor can reset the vote (as can the team leader by entering a new set of FCS marks).

Other features were implemented for academic staff member/tutor access which improved the useability of the FCS software as new versions of the software were introduced. Initially, many students could not login to the system, so the software was changed, adding Servlets which allowed the tutor to display 
students details (such as users passwords, team leader or not, which team a student is in and email user identification) and also the ability to change the user password. The Software was modified to allow all legitimate users to access the system using local LDAP servers (using JNDI[9;10]). Another feature added to the Software was to allow the academic staff member/tutor to email all team members. This was a very useful feature, not just for the FCS, but also to contact team members over other matters arising during the semester.

\subsection{Student and staff feedback on FCS}

A survey was conducted in week 12 of the Autumn semester. The students in this subject came from different backgrounds. Exactly $44.6 \%$ of the responding students were local and had encountered the paper based version of the FCS from the second year design and management subject at UOW. These students were majoring in Electrical, Computer or Telecommunications engineering. The remaining students had not completed the second year subject.

\subsection{Student survey on FCS}

Filtering out those student responses who had not used the paper based FCS before, the question was asked using the Likert scale (the scale was 1-Strongly Disagree, 2-Disagree, 3-Neither Agree or Disagree, 4-Agree, 5-Strongly Agree) whether "The Electronic FCS, compared to the Paper based FCS, was more convenient as teams did not need to meet face to face". This question scored 3.34 on the Likert scale indicating that these students favoured the use of the electronic FCS strongly. Students who had used the paper based FCS were asked to compare the electronic FCS to the paper based FCS using the Likert scale, with a larger value indicating a favourable outcome for the electronic FCS, for various aspects of the FCS. The comparison question asked, for the various categories was "Comparing the Electronic FCS to the paper based FCS indicate for the particular application if you prefer the paper based or the Electronic version of the FCS". The results are shown in Figure 4. The survey revealed that there was no significant difference between the paper and Electronic FCS in terms of discussing the FCS marks, with a very slight preference for the paper based FCS, having a Likert score of 2.41. This was the lowest score of all the categories. In all other categories the electronic FCS was preferred. The next lowest Likert score was 2.93 for the category "resolving differences". The highest Likert score was 4.02 for "more likely to exclude possibility of blank FCS forms being presigned".
All students were asked to make comments on the electronic FCS (regardless of whether they had used the paper based FCS or not). There was a large variation in opinion. The electronic FCS was preferred for ease of use (as students could vote for acceptance over the internet), however the paper based FCS was preferred for discussing the marks assigned. There was not a clear cut opinion expressed either way and there was just as much likelihood that a negative comment by one student about the electronic FCS would have the exactly opposite opinion from another student (depending somewhat on the students' background). One student indicated that there was no good way to apportion marks in group work and the FCS (either in electronic or paper based form) was as good as any other technique. The strongest support came from students who knew how much effort was required to get signatures for the paper based FCS as, strictly speaking, all students were required to sign the paper based FCS before submission of the scores. The most typical response in favour of the electronic FCS was that it was easy to use. One student noted that the electronic FCS had the advantage for the coordinator that they could see the progress in the FCS voting and scores being posted before the final vote occurred (one of the reasons for implementing the system in the first place). There was a strong opinion that the electronic FCS was easily forgotten and students did not know when the team leader had actually placed the scores up on the website for voting.

\subsection{Staff perspective on FCS}

Administering the electronic FCS allowed the academic coordinator to view ongoing discussions between team members (where teams used the FCS discussion tool) and allowed direct intervention in those discussions when needed. It allowed the academic coordinator to see those students who were not participating in the discussion and, in fact, was an early bell ringer for students who decided to withdraw from the subject. Previously, students had withdrawn and neither the academic coordinator or the team members had been informed. The electronic FCS provided extra information regarding this, as these students simply never logged in. The academic staff member can then use the administration screen of the electronic FCS to simply allow the team of students to use a majority vote to submit their electronic FCS. When students did officially withdraw, it was a simple step to remove their information from the 'user.txt' file for the next electronic FCS and all students in the team could see that the withdrawn student was no longer a team member. In later versions of the electronic FCS the 
students could see who the team leader was for a particular FCS. The electronic FCS could also be used to directly contact teams of students without the need to form these email lists in text files (which was the previous situation) as all the team members were shown using their email account user identifiers. From the survey results the major advantage of the paper based FCS was that it encouraged face to face communications. On purpose, the electronic FCS rotated the team leader. This was easy to do by modifying the user.txt file between electronic FCS forms. However, this apparently stopped discussion of FCS scores. In an effort to encourage the FCS discussion a change will be made where the team leader has to affirm that a discussion of the entered marks has occurred in a minuted team meeting. The FCS scores will also need to be a standing item at all minuted team meetings and these minutes are to be attached to the end of semester reports for direct validation of the voted-on scores. In this way the electronic FCS team leader is simply the data entry clerk rather than the author of the FCS marks (which was not the intention of that role in the team). There was one comment from a student that rotating the team leader role was a good idea (from the academic coordinator's perspective it would be easier to nominate one person who maintains that role for the duration of the entire subject, but students are told that they should rotate roles every few weeks and this reinforces that rotation).

The submission of the electronic FCS made updating scores much easier than using the paper based FCS as there was no need to check for signatures or that scores obeyed the rules of the FCS. This was also another reason for pursuing the establishment of an internet based application.

\section{Comparing the Electronic FCS to the paper based FCS indicate for the particular application if you prefer the paper based or the Electronic version of the FCS.}

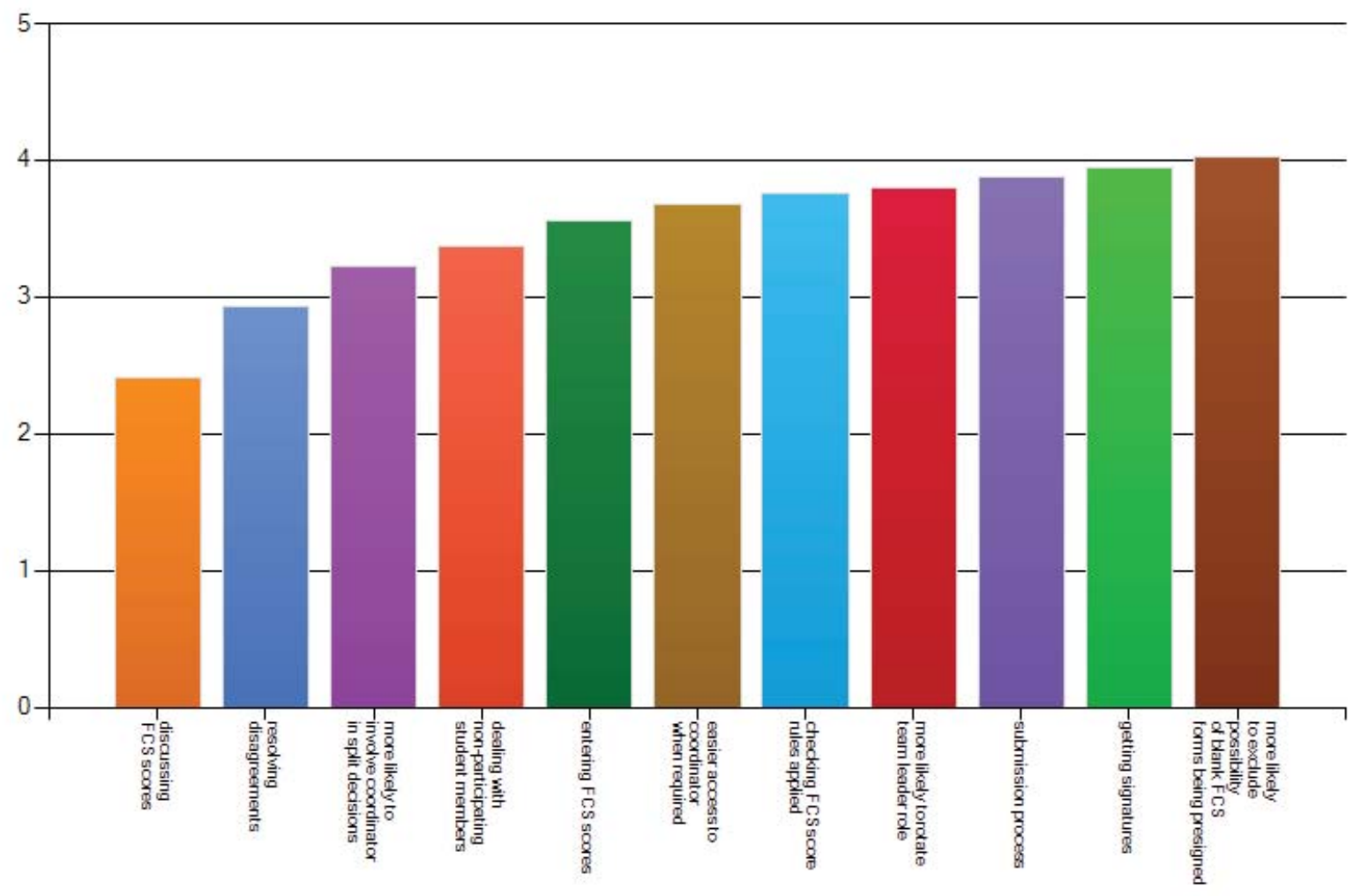

Figure 4: Survey results comparing the electronic FCS (higher Likert values indicates preferred) to the paper FCS (low Likert values indicates preferred) 


\subsection{Conclusion and Future work}

Overall, the deployment of the new electronic FCS has been a success. It allows aspects of student learning in team work to be seen that had not been seen using the paper based FCS. Its major problem lies in getting students to participate in a vote (they often forget to login to vote). As a result of the surveying of students, it has been decided that in Spring Semester of 2010 the team leader will be required to confirm that the marks they have entered have been discussed at an official minuted meeting of the team members (with a majority of voting members having attended). These official minutes (the responsibility of the official secretary) are required to be submitted in fortnightly reports as appendices in the fortnight after the FCS vote has occurred. If there is a discrepancy between these two numbers an explanatory note, signed by all team members, will be required. In this way, it is hoped that the teams will be required to discuss the assigning of all electronic FCS marks before they are entered into the system for submission and voting (which replaces the signature of the previous system).

After the successful implementation of the electronic FCS at UOW, other electronic systems supporting assessment practices at UOW within project based subjects are currently being pursued using Java, tomcat and JSP. One such project is improvement to the existing system by displaying of progress marks for the FCS to teams and academic staff (coordinators and team mentors). Another is development of a project report marking form for staff which results in the automatic displaying of marking forms and comments to all staff and effected students (that is in their teams). It is hoped that this can be interfaced with marking spreadsheets making it easier for the coordinator to deal with larger class sizes and reduce some of the administrative burden that larger class sizes have been imposing.

\section{References}

[1] Jerry M Hatfield and John T Tester, "Assessing Individual performance within a team using peer evaluations," in Conference Proceedings of American Society for Engineering Education Annual Conference and Exposition, Salt Lake City, Utah, USA, June 2004

[2] Mark Freeman, Keith Willey, and Darrall Thompson, "SPARKPlus: Self and Peer Assessment Resource Kit", Website http://spark.uts.edu.au, visited June 2010.

[3] $\mathrm{K}$ Willey and $\mathrm{M}$ Freeman, "Improving Teamwork and engagement: The case for self and Peer Assessment", Australasian Journal of Engineering Education (AAEE) online publication http://www.aaee.com/journal/2006/willey2006.pdf, no. 2006-02, 2006.

[4] Keith Willey and Anne Gardner, "Self and Peer Assessment: A necessary ingredient in developing and tracking students' graduate attributes", in Conference Proceedings of the Research in Engineering Education Symposium, Palm Cove, Queensland, Australia 2009.

[5] Keith Willey and Anne Gardner, "Changing student's perceptions of self and peer assessment", in Conference Proceedings of the Research in Engineering Education Symposium, Palm Cove, Queensland, Australia 2009.

[6] Peter James Vial, "Subject Outline Engineering Design and Management 2", Wollongong: UOW Informatics SECTE, 2010.

[7] "Tomcat 6", Apache Free Software foundation, available http://tomcat.apache.org/, last visited 17th June 2010.

[8] Vivek Chopra, Sing Li, and Jeff Genender, "Professional Apache Tomcat 6", Wiley Publishing Inc (Wrox), 2007.

[9] Danny Ayers, Hans Bergsten, Michael Bogovich, Jason Diamond, Matthew Ferris, Marc Fleury, Ari Halberstadt, Paul Houle, Piroz Mohseni, Andrew Patzer, Ron Phillips, Sing Li, Krishna Vedati, Mark Wilcox, and Stefan Zeiger, "Professional Java Server Programming", Wrox, 1999.

[10] Joel Murach and Andrea Steelman, "Java Servlets and JSP", 2nd ed Murach, 2008.

[11] "NetBeans IDE", available http://netbeans.org/, last visited 17 th June 2010.

[12] "Sun Java", available http://java.sun.com/ , last visited 17th June 2010.

[13] "Class JSONObject", http://www.json.org/javadoc/org/json/ JSONObject.html, last visited 17th June 2010. 